\title{
Use of Blended Learning for Effective Implementation of English-Medium Instruction in a Non-English Higher Education Context
}

\author{
Jin-Hyouk $\operatorname{Im}^{1} \&$ Jeongyeon $\mathrm{Kim}^{2}$ \\ ${ }^{1}$ School of Business Administration, Ulsan National Institute of Science and Technology, Ulsan, South Korea \\ ${ }^{2}$ Division of General Studies, Ulsan National Institute of Science and Technology, Ulsan, South Korea \\ Correspondence: Jeongyeon Kim, Division of General Studies, Ulsan National Institute of Science and \\ Technology, 50 UNIST-gil, Unyang-up Ulju-gun, Ulsan, South Korea. Tel: 82-52-217-2013. E-mail: \\ jkim@unist.ac.kr
}

\author{
Received: February 19, 2015 Accepted: June 12, 2015 Online Published: October 27, 2015 \\ doi:10.5539/ies.v8n11p1 \\ URL: http://dx.doi.org/10.5539/ies.v8n11p1
}

\begin{abstract}
Although researchers agree with the strengths of an English-medium instruction (EMI) in addressing internationalization of a non-English higher education (HE) context, its implementation in classrooms has been widely criticized, mostly because of ineffective delivery of course content and a lack of evidence of English improvement. Grounded upon a critical review of the current state of internationalization of Korean HE and the subsequent examination of supplementary interview data from 15 college students who have taken EMI courses, this study proposes a model which integrates critical factors of EMI into one framework. This model aims at guiding the EMI policy from initiation to implementation. A major feature of this model is blended learning as a strategy to address the shortcomings of current EMI in this context and to facilitate the allocation of diverse online materials to scaffold EMI instruction. The benefits of the approach are presented from the perspectives both of policy-makers and of classroom participants.
\end{abstract}

Keywords: blended learning, English-medium instruction, non-English context, internationalization of higher education

\section{Introduction}

As higher education (HE) in Asian countries has had to become more effective in order to enhance its global competitiveness, Korean higher education institutions (HEIs) have experienced radical changes since the late 20th century. These changes were institutional responses to challenges from outside the campuses. Institutions were urged to reform their English curricula by the Korean government during the years 2008-2012, such that the outcome of English education was to be communicative competence with an emphasis on production skills such as speaking, rather than on comprehension skills. Since internationalization is one of the criteria for ranking HEIs, universities have chosen a policy reinforcing the use of English as a medium of interaction in all sectors within universities including administration, research, and education. This trend accords with the role of $\mathrm{HE}$ as the center of globalization (Altbach, 2004; Knight, 2008), as the world is becoming diglossic with one language for local communication and the other, English, for wider and more formal communication (Coleman, 2006).

English officialization in Korean HE has directly affected education and mandated the language of instruction in classrooms to shift from Korean to English. Many Korean universities have expanded English-medium instruction (EMI), as shown in the recent increase of EMI courses offered by universities. According to a report (Park, 2011), 30\% of all classes offered by the universities in Seoul and 10\% of those in other areas were offered in EMI in 2011. The EMI policy creates an unusual immersion environment in English as a foreign language (EFL) context. Since English is learned in a place where it is not typically used as the medium of ordinary communication, this policy enforces the uses of English in the physical boundary of a classroom. Apparently, EMI may provide ample opportunities for English use along with learning subject areas in the classroom. That is, when English is used in subject area classes, students learn not only the subjects, but also acquire the English language. Thus, the use of English as a second-language (L2) for communicative purposes in the EMI environment helps and motivates learners to develop better English proficiency (Kim, 2002; Kirkgöz, 2005; 
Witty, 2008). However, many researchers have continuously been critical of EMI policies and have argued that there is a lack of evidence to conclude that a statistical correlation can be drawn between educational achievements in subject areas and evidence of effective L2 learning (e.g., Cho, 2012; Jensen \& Johannesson, 1995; Kahng, 1999; Manakul, 2007; Oh \& Lee, 2010; Tsuneyoshi, 2005).

Although researchers have discussed how to enhance EMI by supporting instructors and students in this learning context, the providers of HE still need guidance which addresses specific factors relevant to participants in EMI classes. With this need in mind, this study delineates the recent positioning of HE in Korean society in terms of internationalization and proposes a model in which EMI in a non-English context is systematically approached from initiation to implementation. Included are the qualitative data from interviews with 15 students, who have taken EMI classes in a Korean university with a stringent EMI policy; 100\% English lectures in all the credit courses. In many Asian countries, English proficiency is pursued and cultivated not only for individual academic and occupational purposes, but also as a nation-wide educational drive for the globalization of these societies. The results of this study will provide educators and policy-makers with information on how to implement and further (re)design more effective curricula for EMI courses.

\section{Review of Related Works}

\subsection{Internationalization of Higher Education and English-medium Instruction}

As globally competitive societies have continuously driven HE to be internationalized, internationalization has often been compared with globalization by policy researchers (e.g., Altbach, 2004; Altbach, Reisberg, \& Rumbley, 2009; Knight, 2008; Teichler, 2004). While globalization refers to broad economic, technological and scientific trends (Altbach, 2004), internationalization is defined as the range of policies and programs designed to respond to globalization (Altbach, 2004; Altbach, Reisberg, \& Rumbley, 2009). Knight (2008) confirms the difference between the two terms and elucidates internationalization in terms of relations between nations. Thus, at the institutional level, internationalization encompasses specific actions or services of a community beyond local and national boundaries for the purpose of global citizenship.

These trends directly affect $\mathrm{HE}$ and are largely seen as inevitable. According to Knight (1993), internationalization of $\mathrm{HE}$ is "a process of integrating an international/intercultural dimension into the teaching, research and service function of the institution" (p. 21). Interestingly, although Korean HE institutions have adopted new policies, such as EMI, and offered new programs, such as lab tours to foreign universities, to internationalize the campuses, these policies have been highlighted under the term 'gullobeol-hwa', or 'globalization', rather than internationalization. The recent spread of the term 'globalization' into Korean HE, thus, supports the proposition of Teichler (2004) on the influence of globalization on academics. According to him, globalization is used interchangeably with internationalization, especially for the context of HE. When the term 'globalization' is adopted to describe changes in HE, the changes are targeted towards managerialism and resource acquisition, which are the core elements in the definition of globalization. Some of the mechanisms structuring competition include University rankings (Piller \& Cho, 2013). National university rankings are published annually by two newspapers, The Joongang Ilbo (since 1994) and The Chosun Ilbo (since 2009). One ranking criterion, internationalization, is particularly easy to manipulate and strongly favors EMI. That is, by constituting a covert form of language policy, the trend of globalization has affected Korean HE top-down from university administrators and decision-makers.

One positive aspect of EMI is that it often serves as a cornerstone upon which campuses become internationalized by attracting a larger number of international students than would be the case if no such policy existed. (Hou, Morse, Chiang, \& Chen, 2013; Jensen \& Johannesson, 1995; Manakul, 2007; Tsuneyoshi, 2005). This positive aspect has garnered so much attention among policy makers that many Korean universities have voluntarily expanded EMI (Park, 2011). However, researchers have pointed to ineffective delivery of course content and the lack of evidence of English improvement in EMI in practice (e.g., Akar, 2010; Chang, 2010; Hou, 2011; Hou et al., 2013; Hu \& Alsagoff, 2010; Jensen \& Johannesson, 1995; Kim, 2011; Manakul, 2007; Manh, 2012; Tatzl, 2011; Tsuneyoshi, 2005). Kang and Park (2005) highlighted the lack of linguistic development, as the students rarely received feedback on language forms in oral and written activities. Kim (2002) investigated students' evaluations of 55 English-medium lectures at a university in Korea. While the students positively evaluated the enthusiasm of the instructors and the enhanced motivation brought on by the new experience that they had in EMI classrooms, they noted the problems of an additional workload and understanding the lectures in the classrooms. A noteworthy point was that in the EMI classrooms, the students paid more attention to content than to language itself. Thus, against the expected development of English in an ESL environment, the EMI policy was not effective in enhancing language proficiency. 
According to Jenkins (2010), universities with an EMI policy perceive themselves to be global. What the institutions have ignored has been truly global language policies and practices which accommodate multilingual academic communities and appropriate pedagogy in the communities (Jenkins, 2010; Onsman, 2012). L2 researchers have suggested that certain preconditions ought to exist for an EMI policy to be successful for students' acquisition of the subjects and the language. These conditions include the speaking ability of the instructors; practicalities of the programs; linguistic and academic assistance for the students; and systematic services for nonnative instructors (Cho, 2012; Kang \& Park, 2005; Kim, 2002; Kong \& Hoare, 2012; Witty, 2008). Erling and Hilgendorf (2006) took a close look at EMI's impact at a German university. According to their study, the most important problems in EMI implementation included (1) students' and some instructors' inadequate language skills and (2) insufficient opportunities for appropriate language training, particularly for those in need. Researchers have suggested that institutions should offer systematic services for the instructors along with a new English curriculum to improve the English proficiency of the EFL learners, based upon information garnered from the examination of students' and instructors' beliefs about EMI (Cho, 2012; Kim, 2014; Kim, Tatar, \& Choi, 2014; Manh, 2012).

\subsection{Blended Learning}

As Altbach (2004) claims, information and communication technology (ICT) accelerated the globalization of education and as a result, the tremendous flow of students and highly educated personnel across borders occurred. The recent prominence of ICT in Korea has transformed the educational environment in which teaching and learning takes place. In a blended learning model, an instructor incorporates online content and blends it into the entire class. This ICT-incorporated learning context has been favored because it maintains human contacts while capturing the flexibilities of online learning (Collis, 2003; Jones \& Lau, 2010). Authentic tasks that are likely to be encountered in life may be offered and completed online, which has been found to increase students' motivation to learn (Han, 2001). Since ICT-incorporated curriculum enables learners to control the technology and ultimately their learning, unlike traditional teacher-centered learning, a class can be more learner-centered.

A blended learning model has recently been in use for enhanced interaction and collaboration in diverse educational contexts (e.g., Shin, Peachey, \& Tuck, 2002; Thang et al., 2013; Wold, 2011). Researchers have rigorously shown the positive effects of online learning on learning processes and outcomes (e.g., Baker \& Watson, 2014; Lawton et al., 2012; Ng'ambi \& Lombe, 2012; Park \& Lim, 2013; So \& Bonk, 2010; Spector, 2013). Online learning activities, included in blended learning, can improve students' participation in learning (Jones \& Lau, 2010), and ultimately increase learner autonomy (Sun, 2010). On the virtual station, students were also found to collaborate to deal with complex problems (Baker \& Watson, 2014; Hastie, Hung, Chen, \& Kinshuk, 2010). Thang and colleagues (2013) examined EFL college students' evaluations of online course books and activities in an English course following a blended learning approach. Both high and low proficiency groups positively evaluated the online portion in terms of meeting their language and personal needs. Many Korean universities have considered and/or have actively adopted online programs in foreign language classes. Some of the studies have found that online learning environments received positive feedback from the students in terms of collaboration between the students for online tasks (Ihm, 2005; Kim, 2010; Shin et al., 2002; So \& Bonk, 2010).

Researchers of educational technology have noted that learning aided by technology can have positive effects on learning outcomes when the goal of using technology is shared among policy makers, instructors and students, in the dynamics of the social interactions of the school system (Byrom \& Bingham, 2001; Dede, 1998; Lim, Zhao, Tondeur, Chai, \& Tsai, 2013). Lim and colleagues further emphasize that the impact of technology use on learning is not determined simply by the particular technology used, but rather is mediated by environmental factors (2013). For example, blended learning needs to ensure that students experience social presence online as they do in offline classroom interaction (Castle \& McGuire, 2010; Jusoff \& Khodabandelou, 2009). It is also crucial to consider how instructors and students alike perceive uses of a certain technology not only in terms of its effects on learning outcomes, but also of its usefulness and ease of use (Tselios, Daskalakis, \& Papadopoulou, 2011).

As reviewed above, although the studies on EMI implemented in a non-English context have addressed various challenges for an EMI policy in HE, few studies exist that delineate factors implicit in EMI or suggest a comprehensive model which can be applied to the implementation of an EMI policy in a non-English context. As Yamat and colleagues (2014) state, a language policy, without a clear framework, is interpreted differently by different educational institutions and, thus, may engender different outcomes in the target language proficiency. An explicit guideline is critical for bilingual education to be successful in a non-English context (Yamat, Umar, 
\& Mahmood, 2014). Given this need, we propose a model for an EMI that can be applied to and revised according to different educational contexts. This proposed framework is expected to help policy-makers and educators plan and implement the policy and furthermore ensure that the policy sustains in an ever changing HE system undergoing internationalization.

\section{Methods}

\subsection{Context and Participants}

Although we propose a model mostly based upon the researchers' critical examination of the findings of the previous research, the model is also supported by some qualitative interview data of 15 college students who have taken all the courses in English for more than two semesters. At the time of the research, they had taken required courses in Arts and Humanities and 2-5 major-specific subject courses. As shown in Table 1, their majors were identified either as business management or as engineering, with experiences of EMI for 2-3 semesters.

Table 1. Background information

\begin{tabular}{llc}
\hline Characteristics & $\begin{array}{c}\text { Frequency (\%) } \\
(\mathrm{N}=15)\end{array}$ \\
\hline \multirow{2}{*}{ Gender } & Male & $11(73.3)$ \\
& Female & $4(26.6)$ \\
\multirow{2}{*}{ Affiliation } & Management & $10(66.6)$ \\
& Engineering & $5(33.3)$ \\
\hline
\end{tabular}

Built in 2009, with a policy of internationalization of the university, the university adopted an EMI policy from the outset. The research site is a science and engineering university which does not have undergraduate departments or majors in the humanities and social sciences other than business management. As of 2013, the university had about 3,000 undergraduate and 1,500 graduate students. Students, predominantly science and engineering majors, not only use class materials, including textbooks, written in English, but also take exams in English. However, outside the classrooms, professors and students have no restrictions on the medium of communication, and speak Korean or English during office hours.

This HE context features a blended learning model in education. Unlike the EMI policy, blended learning was adopted voluntarily by classroom instructors with practical support from the university. About $20 \%$ of the classes were taught through a blended learning approach in spring 2013. The interviewed students comprised of 11 male and 4 female sophomores who majored in either Business Management or various engineering fields. At the time of the interview, none of them had lived in an English-speaking country for more than 6 months.

\subsection{Procedure and Data Analysis}

We recruited students for an interview which was conducted individually or in a group of 2-3 with the researchers. During the interview, the interviewees discussed their experiences with EMI, given the researchers' questions on their thoughts about taking subject courses in English. The audio-recorded interviews were transcribed, and then translated into English for cross-examination with the quantitative data.

The qualitative data analysis (Merriam, 2009) included reading the entire data set several times and capturing themes through the several rounds of reading. We then applied the initial coding categories back to the original data to evaluate their usefulness. The categories and subsequent themes emerging from the categories are incorporated into and presented along the proposed model of EMI.

\section{Reconceptualization of EMI in a Non-English Context}

\subsection{Korean HE in the 21st Century and EMI}

Now that Korea is an economically advanced, industrialized nation, Korean universities have reached a significant level from the academic point of view. The scholars and specialists in different academic disciplines acquired degrees from western countries with well-established educational resources and credentials. As shown in Figure 1, the number of Korean college students studying abroad for degrees and training purposes reached over 200,000 in 2007, with an all-time high in 2011. As of 2012, the U.S. was ranked as the most favored 
destination by Korean students studying abroad, while China ranked just behind the U.S. (Figure 2).

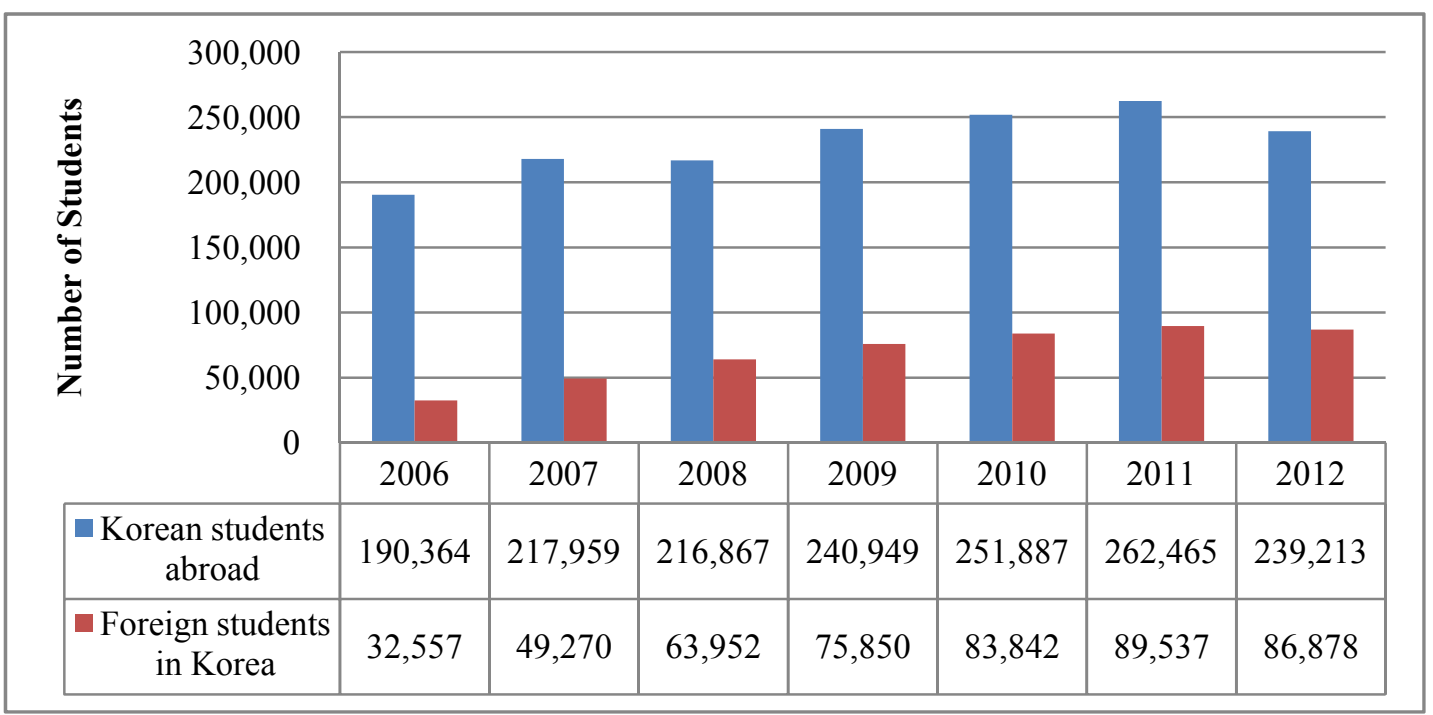

(Data source: National Index web site (http://www.index.go.kr/) of the Statistics Korea)

Figure 1. Number of Korean college students studying abroad and international students in Korea (for both degrees and training programs)

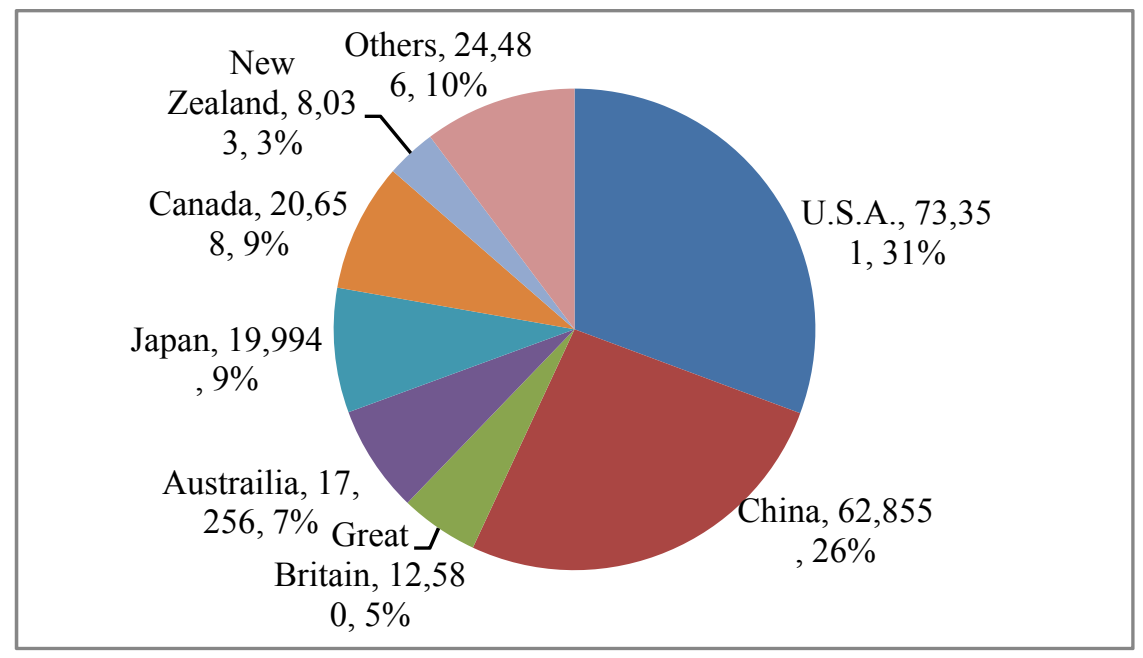

(Data source: National Index website (http://www.index.go.kr/) of the Statistics Korea)

Figure 2. Number of Korean students studying abroad (as of April 1, 2012)*

A growing phenomenon in Korean HE is that domestic universities establish ties with foreign universities in order to reverse the study-abroad preponderance. For example, State University of New York opened a campus in the Songdo International City, Incheon, a metropolitan city in South Korea, in 2012. Moreover, Yonsei University, one of Korea's most prestigious private universities, launched a residential college program in 2014, in which freshmen stay at the Songdo International Campus to receive their first-year education. According to Altbach, Reisberg and Rumbley (2009), this establishment of university branch campuses (usually from a developed country) in another host country is one of the major aspects of the globalization of HE. Most of these programs are taught in English, particularly in such high demand fields as management studies or information technology (Altbach, Reisberg, \& Rumbley, 2009).

These efforts to replace the import of HE with domestic initiatives are likely to have only a limited effect on education and the economy. Given the shared recognition of this limitation, Korean HEIs, with governmental 
support, have attempted to recruit international students to make Korean campuses academically attractive and competitive, by means of an EMI policy. The number of international students in Korean higher education has significantly grown due to their interest in Korea's miraculous economic development and employment opportunities at Korean companies. The number of international students studying at Korean universities has increased from 32,557 in 2006 to 86,878 in 2012, a 2.7-fold increase (Figure 1). This rapid growth increased the ratio of international students in Korea to Korean students studying abroad from $17.1 \%$ in 2006 to $36.3 \%$ in 2012 . However, the trade deficit between the overseas expenditure by Korean students abroad and the domestic income from international students in Korea was very significant (Figure 3). For example, in 2012, expenditure overseas amounted to 3.35 billion dollars, compared with the income from international students in Korea reaching merely 38 million dollars.

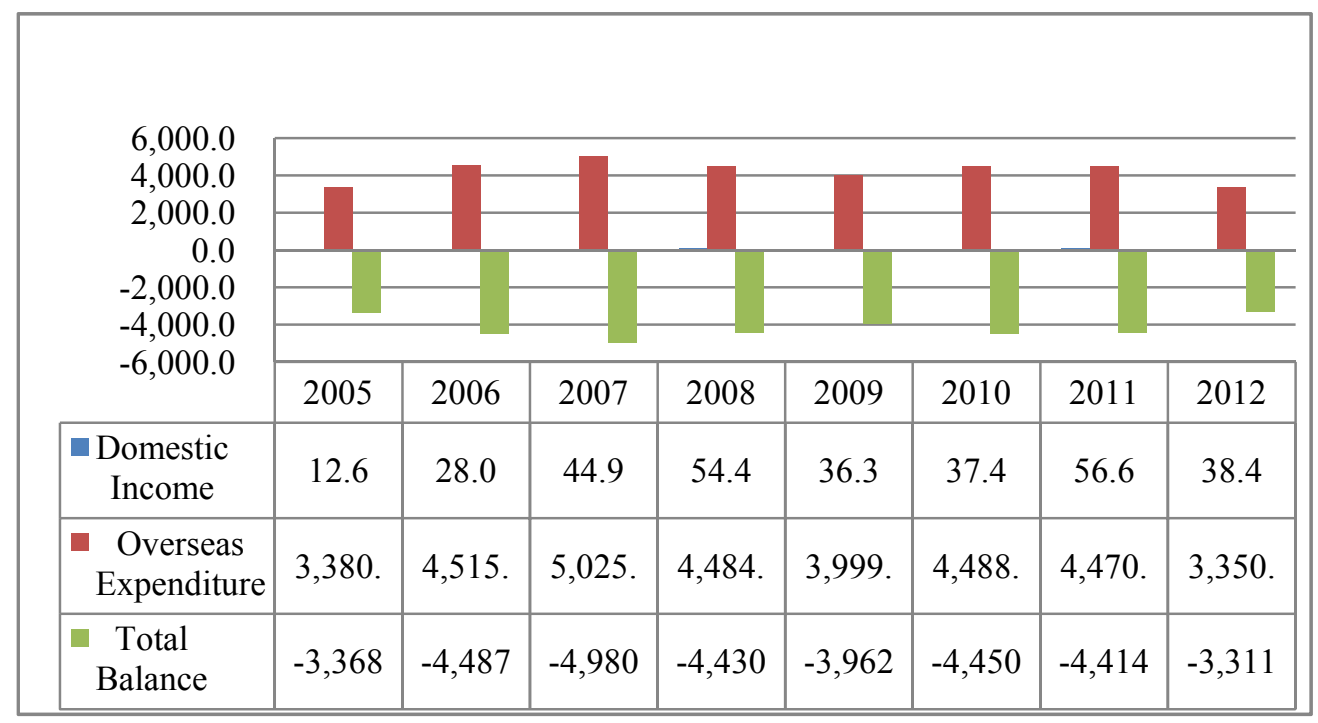

Figure 3. Income and expenditure for education (by million dollars)

Note. Income and expenditure indicate total amounts paid by students of all levels including colleges and all types of short and long-term trainees.

Apparently, since HE in a non-English HE context is increasingly urged to be globally competitive, an EMI policy, because of its top-down initiation and implementation, is expected to remain in the educational context (Kim \& Choi, 2014; Kim, Tatar, \& Choi, 2014, Piller \& Cho, 2013). Despite the growth in the portion of EMI courses, Korean universities have had difficulty implementing the EMI policy. The policy has been mainly socio-political for the sake of university rankings, without sufficient consideration of participants in and factors relevant to EMI in the EFL community (Byun et al., 2011; Kim \& Choi, 2014; Kim, Tatar, \& Choi, 2014, Piller \& Cho, 2013). The policy needs practical guidelines which consider the perspectives of the participants in EMI, followed by optimal, institutional support, to achieve the desired outcomes of being globally competitive.

\subsection{Students' Perceptions of EMI}

According to Han and colleagues, students taking an EMI course hold a more positive view of English lectures than instructors do (Han, Kim, Maeng, \& Kim, 2011). Likewise, we observed students who willingly decide to enroll in EMI courses likely to face the most difficulty during the first semester because they have yet to familiarize themselves with the delivery of lectures in English. However, after having completed their first semester, it has frequently been reported that students feel more confident as their grades are better than what they had originally expected. This is not because their understanding of the English lectures increased drastically in just one semester, but because they were exposed to various learning strategies within an accommodative setting to help them become academically successful. Students' English language proficiency also grew because of repeated exposures to English parlance. The following is an evaluation of a student who took all the subject classes through EMI for two semesters.

"I could merely understand $60 \%$ of the lectures, when taking the EMI class first time. I felt ashamed. But after a year or so, I could understand about 70 80\%. I felt that my English was getting better, although slowly." (ST02: 
Female, Business management, 3 semesters of EMI)

As might be expected, it is more difficult for students to take lectures in English than in Korean at Korean universities. But it is easier than going abroad to study, as one of the interviewees commented:

"Taking chemistry or biology in English is difficult. But there are international students in my biology class, like Lu. She's here in Korea taking classes in English, and English is not her first language, either. I guess my job is much easier than hers." (ST 01: Male, Business management, 4 semesters of EMI)

Apparently, some students, being autonomous in learning, developed their own learning strategies in order to overcome the difficulty understanding English lectures. They read books or supplementary materials, sought help from instructors and teaching assistants, or cooperated with other students by forming study groups with fellow students. As follows, one of the interviewed students addressed a strategy she used to handle the difficulty common in EMI classrooms.

"I'm not confident in using English. Especially in my major courses, I feel so terrible when I have to leave the classroom without understanding anything. I need to make twice the effort to understand the lectures delivered in English by a Korean professor. These days, I record all the lectures and listen to them in my dorm room." (ST08: Female, Engineering, 3 semesters of EMI)

In sum, we note that the EMI context, although difficult, was perceived as a challenge to be handled. If it is effectively designed and systematically practiced, the EMI policy may create a positive learning context of the subject and the foreign language. In the next section, we propose a framework which analyzes a course for EMI.

\subsection{An Analytical Framework for EMI}

Given the positive perceptions of EMI, a framework for EMI, as we propose, examines the feasibility of EMI for a subject class. It addresses three key elements of the English lectures in an integrated manner: (1) the level of internationalization of the subject, (2) English proficiency of the instructor, and (3) English proficiency of students. Each of the elements is examined in relation to the others. The first element, the level of internationalization of the subject, refers to the extent to which the subject is accessible to international students. That is, the internationalization level of the subject will be high if the content is not limited to the domestic boundary, such as basic science courses. By contrast, when the content requires significant regional background knowledge, such as Korean history, the class is to be said less internationalized.

The other two elements, the students' and instructors' English proficiency, have been noted by researchers the most over the past decade (Cho, 2012; Erling \& Hilgendorf, 2006; Kang \& Park, 2005; Kim, 2002; Kong \& Hoare, 2012; Witty, 2008). Classroom instructors' different levels of English proficiency affect students' perceptions of the EMI class in terms of English language development as well as content learning. One of the interviewees commented on this issue in the following excerpt.

"We have some professors constantly making grammatical errors in their speech, and on their lecture slides. We, as students, might accept those errors as the right way of speaking English." (ST 07: Female, business management, 3 semesters of EMI)

This analytic framework for EMI shown in Figure 4, visualizes how these three elements might interact with each other and presents three-dimensional framework which has eight discernible domains. This framework can be used to examine each class in terms of the three elements, so that EMI is confirmed useful. For example, domain 1 is one where the English proficiency of the instructor and students is superb and the internationalization level of the class is high. Accordingly, EMI should draw positive outcomes in a class of this domain. Meanwhile, domain 8 is characterized by the poor English proficiency of the instructor and students while the internationalization level of the class is low. Thus, EMI, if implemented in this class, is expected to be least effective to learning processes and outcomes. 


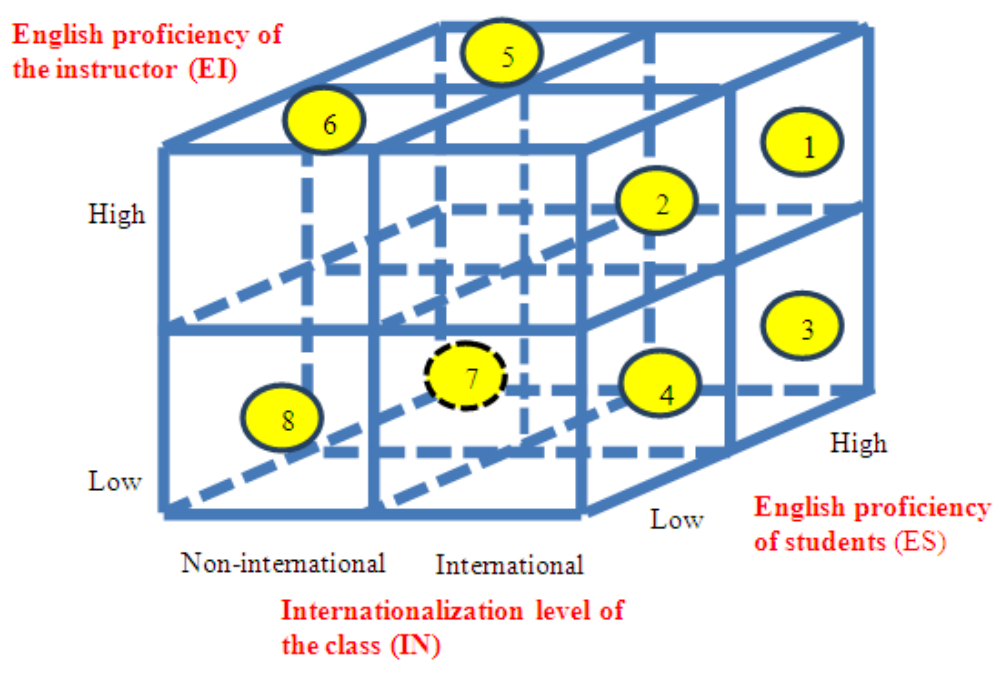

Figure 4. Analytic framework for EMI

\subsection{EMI in Practice}

A major misconception of EMI is that all class activities, such as lectures, question and answer periods, discussions, presentations, assignments, need to be carried out solely in English. In our proposed model, EMI may be implemented in various manners in terms of the portion of the English language used in and out of classroom. A proper implementation method needs to be selected based upon the analysis of the level of each of the three elements in the analytic framework of surroundings of the EMI class: the level of internationalization of the class (IN); English proficiency of the instructor (EI), and English proficiency of students (ES). In other words, a selection of a method for the implementation of EMI may be closely tied to the characteristics of each of the eight domains. When a class falls into domain 1 (high levels of IN, EI, and ES), then EMI can be fully implemented. In a class in which both the instructor and the students have a high level of English proficiency, while the subject is low in internationalization of the content (domain 5), EMI may be implemented only partially; students may be allowed to speak their first language in some of the class activities. However, when a class belongs to domain 3, i.e., high IN, low EI, and high ES, EMI is not to be implemented. This flexibility in implementation could help reduce the negative effect in which learning is ineffective due to the use of English. Further, EMI can be incorporated into different class environments in a systematic manner (Table 2).

In practice, one of the interviewed students pointed to the difficulties he experienced in a course on the history of science. His instructor's English proficiency was relatively low, and the themes of the class required students to participate in discussions of current, local communities along with historical episodes in science.

"First of all, it was very difficult to understand what she was lecturing in English. And the discussion required us to bring to class abundant knowledge of what was going on here in Korea. So we were going back and forth between now and the Chosun dynasty. We also had to understand European history. I think that course shouldn't be offered to freshmen to whom English lectures are totally new and challenging." (ST 15: Male, business management, 2 semesters of EMI)

According to the analytic framework, this course belongs to domain 8, which indicates low internationalization of the subject and low English proficiency of instructors and students. EMI may not be recommended for this domain; EMI may not create an efficient learning context. As indicated by the interviewee, when a strong version of EMI is enforced and no use of the local language is allowed, it resulted in unsuccessful interaction and learning in a classroom. However, a comprehensive denial of EMI may create a more serious concern with regard to the students' learning opportunities. These learners with low-level English proficiency may suffer from a lack of exposure to the target language while other advanced students get more input and opportunities to enhance their proficiency. Some interventions can be made to address this concern, such as providing lecture videos in Korean for preview or review, in a partially EMI classroom. As a way to provide useful assistance for these contexts, we propose in the next section an approach which incorporates ICT into the curriculum. 
Table 2. Characteristics of eight domains for EMI

\begin{tabular}{lcccc}
\hline Domain & $\begin{array}{c}\text { Internationalizati } \\
\text { on of Class (IN) }\end{array}$ & $\begin{array}{c}\text { English Proficiency } \\
\text { of the instructor (EI) }\end{array}$ & $\begin{array}{c}\text { English Proficiency of } \\
\text { the students (ES) }\end{array}$ & $\begin{array}{c}\text { Suggested EMI } \\
\text { Implementation }\end{array}$ \\
\hline 1 & High & High & High & Full \\
2 & High & High & Low & Partial to Full \\
3 & High & Low & High & No EMI? \\
4 & High & Low & Low & No EMI? \\
5 & Low & High & High & Partial \\
6 & Low & High & Low & Partial \\
7 & Low & Low & High & Partial \\
8 & Low & Low & Low & No EMI? \\
\hline
\end{tabular}

\subsection{Blended Learning in Implementation of EMI}

In an EMI environment, instructors' command of English is critical for students' learning outcomes as indicated by researchers (Cho, 2012; Kang \& Park, 2005; Kim, 2002; Kong \& Hoare, 2012; Vinke, Snippe, \& Jochems, 1998; Witty, 2008). According to Vinke and colleagues, teaching in a foreign language reduces the redundancy of instructors' subject matter presentation, speech rate, their expressiveness, and their clarity and accuracy of expression (1998). It is possible to measure the expected outcome of EMI by comparing the English proficiency of a nonnative English-speaking instructor with that of a native English-speaking instructor. The same measure can be applied to students as well. For example, as presented in Table 3, if the EMI instructor's English proficiency is $70 \%$ of a native English-speaking instructor and the participating students' ability to comprehend EMI is $70 \%$, the expected outcome is $49 \%$ in this class, which is very poor (context 1 ). Even when the instructor's and students' proficiencies are increased to $80 \%$, the expected learning outcome remains a low $64 \%$ (context 2). However, when the very same students study abroad, and take lectures delivered by a native speaker, the learning outcome is $70 \%$ (context 3). On the contrary, when a nonnative English-speaking instructor lectures in a U.S. university class, which is a not uncommon, a native English-speaking student typically understands all of the $70 \%$ (context 4). In the same line, when a nonnative, English-speaking instructor gives lectures to nonnative English-speaking students in a U.S. university, the context is very likely to be the same as an EMI class found in a Korean university.

As a strategy to complement the poor outcomes due to the instructor's lack of English proficiency, we propose the use of ICT in teaching and learning. Previous studies have shown a blended learning approach may provide a facilitative learning context for the students who favor flexibility and convenience (Lee \& Chong, 2007; Deghaidy \& Nouby, 2008; Wing \& Khe, 2011). Added to this benefit, there is a consensus that this approach encourages students to become active participants in knowledge construction by facilitating online participation, and increasing motivation to learn through diverse offline interaction with instructors and peers (Deslauriers, Schelew, \& Wieman, 2011; Rooney, 2003). Deslauriers and colleagues (2011) measured the learning of a specific set of topics of a physics course in traditional versus non-traditional, student-centered classes. In the student-centered, pre-class, activity-laden instructions, students were asked to study the assigned reading materials available online, and participated in small group discussion-type activities with multiple instructors. This blended learning design increased student attendance, resulted in higher engagement, and improved learning outcomes (Deslauriers, Schelew, \& Wieman, 2011).

Table 3. Expected learning outcomes in a traditional EMI model

\begin{tabular}{llll}
\hline Context & English delivery of Instructor (EI) & Students' understanding of lecture (SU) & $\begin{array}{l}\text { Expected outcomes } \\
(\text { EI x SU) }\end{array}$ \\
\hline 1 & $70 \%$ & $70 \%$ & $49 \%$ \\
2 & $80 \%$ & $80 \%$ & $64 \%$ \\
3 & $100 \%$ & $70 \%$ & $70 \%$ \\
4 & $70 \%$ & $100 \%$ & $70 \%$ \\
\hline
\end{tabular}


In the current study, some of the interviewed students were found to have positive attitudes towards blended learning. One of the students taking Physics I, in which blended learning is adopted with online pre-class activities, commented on the use of learning materials available on the learning management system as follows.

"The assistant instructor for the business class is very helpful. She always uploads handouts to the system and is always ready to answer students' questions. I think that is a great plus in this class." (ST03: Female, Engineering, 3 semesters of EMI)

This ICT-incorporated, blended learning approach can address some of the weaknesses associated with EMI in a non-English context. We have noted that it is virtually impossible to drastically improve the English proficiency levels of an instructor and students in a short-term period. In this model, ICT is used for $50 \%$ of the classroom instruction while the other $50 \%$ of instruction occurs online. That is, by means of a blended learning approach, online instruction will be provided in a lecture recorded by native English-speaking instructors, e.g., Open Course Ware of MIT and other English lectures that are available online. Using these materials is expected to improve the students' learning in two aspects: learning a subject taught by a native English-speaking instructor and using the recorded online material as many times as is necessary to develop mastery of a particular subject area. As shown in Table 4, ICT may improve the learning outcomes in the two contexts which include nonnative English-speaking students and instructors (contexts 1 and 2). In context 1, when the instructor's ability to deliver a subject in English is $70 \%, 50 \%$ of the lecture may be complemented by online materials, the instructor's English delivery increases to $85 \%$, which is a $15 \%$ point increase of the outcome of the traditional class. Students' understanding level may increase from $70 \%$ to $85 \%$. Thus, the learning outcome increases from $49 \%$ to $72.25 \%$. In the same manner, in context 2 , a blended learning approach will significantly enhance the learning outcome from $64 \%$ (Table 3) to $81 \%$ (Table 4).

Table 4. Examples of ICT-incorporated blended EMI class

\begin{tabular}{lccc}
\hline Context & English delivery of Instructor (EI) & $\begin{array}{c}\text { Students' understanding of lecture } \\
(\mathrm{SU})\end{array}$ & $\begin{array}{c}\text { Expected outcomes } \\
\text { (EI x SU) }\end{array}$ \\
\hline & Human ICT & Human $\quad$ ICT & \\
1 & $(70 \% \times 50 \%)+50 \%=85 \%$ & $(70 \% \times 50 \%)+50 \%=85 \%$ & $72.25 \%$ \\
2 & $(80 \% \times 50 \%)+50 \%=90 \%$ & $(80 \% \times 50 \%)+50 \%=90 \%$ & $81 \%$ \\
\hline
\end{tabular}

\subsection{Stages of Implementation of EMI}

As shown in the previous sections, the proposed model highlights the factors that are to be considered from the initiation to the implementation of an EMI policy. The entire process may be structured into several stages (Figure 5). First, the educators set the priorities and assess an individual context in terms of the three elements in the proposed framework (internationalization of the subject, the English proficiencies of the instructors, and that of the students) with the proposed analytic framework. Next, the educators select the most appropriate means for the optimal delivery of EMI. In the next stage, a blended learning model may be reviewed for a possible application into the EMI course. In this stage, it should also be noted that, despite the stated strengths of blended learning, students may experience apprehension, anxiety and confusion when interacting with online materials (Burgess, 2008). Thus, curriculum designers and classroom instructors need to (re)assess individual contexts carefully in terms of online resources available for a subject and the classroom instructor's and students' attitudes towards, and capabilities of, using online materials. This assessment will help design how on- and offline materials and activities will be composed and integrated into teaching various topics.

The final stage concerns the selection of appropriate incentives for the instructor and students in the EMI classroom. Positive incentives, such as financial compensation and a reduction in teaching hours, may encourage the instructor to actively redesign his or her course in order to enhance the EMI class and to better accommodate students' needs. Finally, after it is properly implemented according to the stages, EMI practices in a classroom may be evaluated, which will provide crucial information for the redesign of the classes and more effective EMI in an EFL context. This model, thus, ultimately functions as a guideline on how to address the constraints in different EMI contexts. 


\section{Examination of a class}

- The level of internationalization of the class

- English proficiency of the instructor

- English proficiency of students

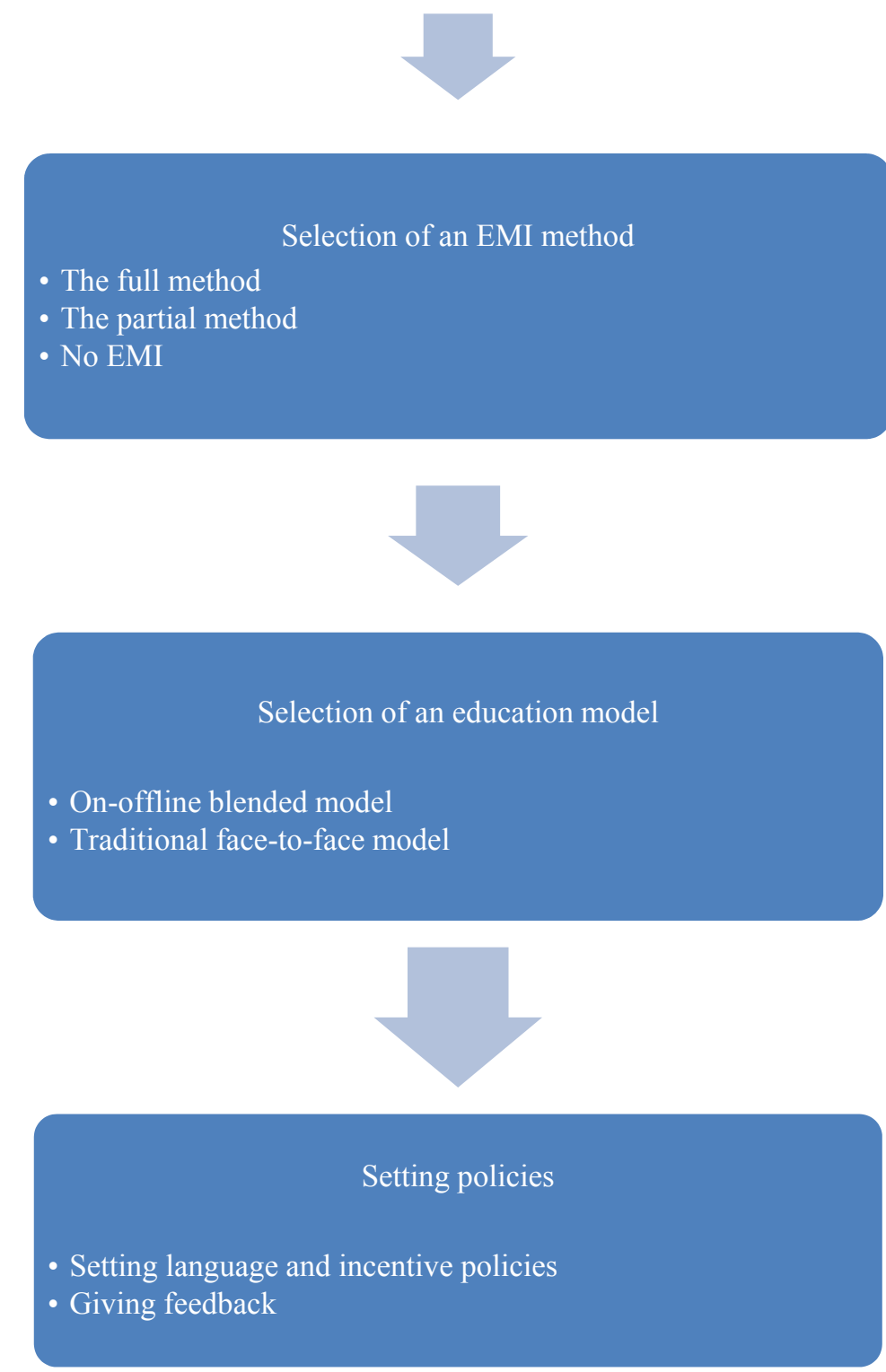

Figure 5. Four-stage model for EMI courses

\section{Conclusion}

Since the concept of globalization has quickly penetrated into HE, HE has recognized the need for a change and sought to create a global academic environment (Altbach, 2004). In the midst of the increased complexities of HE, as Coleman (2006) claims, English is now more than a foreign language. Instead, it functions as the lingua franca, a universal language needed for global business and education. It is imperative to establish a more democratic model of English as lingua franca amid the growing importance of the role of English (Coleman, 2006). This study responds to this need, and proposes a constructive, systematic model to implement EMI for HE in an EFL context. 
Instructors and students are both stakeholders and thus need to share a common vision with regards to global competitiveness. EMI, apparently, provides the students with more contact with the target language and the kind of stimulation necessary to better master the target language. Moreover, as Zhao and Coombs (2012) elucidate, a teaching method, if properly selected and implemented, may bring about a personal paradigm shift in the student towards becoming a global citizen. We have shown that EMI can help Korean students to become more globally competitive, while simultaneously reducing the high costs associated with studying abroad. The negative aspects of EMI revealed in the previous studies on this subject may be thwarted by deliberately adopting this model. Further, universities can cope with inequalities in the numbers between incoming international students and outgoing students by means of EMI. Internationalization of HE may be accelerated further if the universities approach the policy systematically and adopt the proposed model voluntarily.

The suggested model, based upon the literature on EMI, blended learning, and supplementary interviews with a small group of university students, is subject to limitations. For example, intervention to address instructors' low English proficiency may not function precisely as indicated by the calculated percentages. The model, therefore, needs to be redesigned according to the data collected by researchers and educators. Further research may examine how the proposed model, if applied to various non-English contexts, would affect the learning processes and outcomes in EMI courses. With quantitative and qualitative methods, the effects on the development of the English language proficiency and content learning may be investigated. Students' and instructors' feedback, such as changes in perception, in redesigning the EMI classes, are also to be examined, so that the changes will be beneficial to every party involved - policy-makers of higher education, instructors and students.

\section{References}

Akar, H. (2010). Globalization and challenges for developing countries: The case of Turkish higher education. Asia Pacific Education Review, 11, 447-457. http://dx.doi.org/10.1007/s12564-010-9086-0

Altbach, P. G. (2004). Globalisation and the university: Myths and realities in an unequal world. Tertiary Education \& Management, 10(1), 3-25. http://dx.doi.org/10.1080/13583883.2004.9967114

Altbach, P. G., Reisberg, L., \& Rumbley, L. E. (2009). Trends in global higher education: Tracking an academic revolution. A Report Prepared for the UNESCO 2009 World Conference on Higher Education

Baker, W., \& Watson, J. (2014). Mastering the online Master's: Developing and delivering an online MA in English language teaching through a dialogic-based framework. Innovations in Education and Teaching International, 51(5), 483-496. http://dx.doi.org/10.1080/14703297.2013.796712

Burgess, J. (2008). Is a blended learning approach suitable for mature, part-time finance students? The Electronic Journal of e-Learning, 6(2), 131-138.

Byrom, E., \& Bingham, M. (2001). Factors influencing the effective use of technology for teaching and learning: Lessons learned from SEIR*TEC Intensive Site Schools. Greensboro, NC: SERVE.

Byun, K., Chu, H., Kim, M., Park, I., Kim, S., \& Jung, J. (2011). English-medium teaching in Korean higher education: policy debates and reality. Higher Education, 62, 431-449. http://dx.doi.org/10.1007/s10734-010-9397-4

Castle, S., \& McGuire, C. J. (2010). An analysis of student self-assessment of online, blended, and face-to-face learning environments: Implications for sustainable education delivery. International Education Studies, 3(3), 36-40. http://dx.doi.org/10.5539/ies.v3n3p36

Chang, Y. (2010). English-medium instruction for subject courses in tertiary education: Reactions from Taiwanese undergraduate students. Taiwan International ESP Journal, 2(1), 55-84.

Cho, D. (2012). English-medium Instruction in the university context of Korea: Tradeoff between teaching outcomes and media-initiated university ranking. The Journal of Asia TEFL, 9(4), 135-163.

Coleman, J. A. (2006). English-medium teaching in European higher education. Language Teaching, 39(1), 1-14. http://dx.doi.org/10.1017/S026144480600320X

Collis, B. (2003). Course redesign for blended learning: Modern optics for technical professionals. International Journal of Continuing Engineering Education and Lifelong Learning, 13(1/2), 22-38. http://dx.doi.org/10.1504/IJCEELL.2003.002151

Dede, C. (1998). Learning about teaching and vice versa. Paper presented at Conference of Society for Information Technology in Education. Washington D.C., USA.

Deghaidy, H. E., \& Nouby, A. (2008). Effectiveness of a blended e-learning cooperative approach in an Egyptian 
teacher education programme. Computers \& $\quad$ Education, 58-1006. http://dx.doi.org/10.1016/j.compedu.2007.10.001

Deslauriers, L., Schelew, E., \& Wieman, C. (2011). Improved learning in a large-enrolment physics class. Science, 332, 862-864. http://dx.doi.org/10.1126/science.1201783

Erling, E. J., \& Hilgendorf, S. K. (2006). Language policies in the context of German higher education. Language Policy, 5, 267-292. http://dx.doi.org/10.1007/s10993-006-9026-3

Han, H., Kim, H., Maeng, E., \& Kim, S. (2011). Need Analysis and Support for Effective EMI. Aju University Policy Research Report.

Han, T. (2001). Training materials of ICT application education for supervisors, research report. Ministry of Education \& Human Resources Development, Korea Education \& Research Information Service.

Hastie, M., Hung, I-C., Chen, N-S., \& Kinshuk. (2010). A blended synchronous learning model for educational international collaboration. Innovations in Education and Teaching International, 47(1), 9-24. http://dx.doi.org/10.1080/14703290903525812

Hou, A. Y. (2011). Quality assurance at a distance: international accreditation in Taiwan higher education. Higher Education, 61, 179-191. http://dx.doi.org/10.1007/s10734-010-9331-9

Hou, A. Y. C., Morse, R., Chiang, C., \& Chen, H. (2013). Challenges to quality of English medium instruction degree programs in Taiwanese universities and the role of local accreditors: A perspective of non-English-speaking Asian country. Asia Pacific Education Review, 14(3), 359-370. http://dx.doi.org/10.1007/s12564-013-9267-8

Hu, G., \& Alsagoff, L. (2010). A public policy perspective on English medium instruction in China. Journal of Multilingual and Multicultural $\quad$ Development, $365-382$. http://dx.doi.org/10.1080/01434632.2010.489950

Ihm, H. (2005). The study of development of multimedia-assisted general English courses for college students: On the basis of needs analysis. English Language Teaching, 17(3), 235-257.

Jenkins, J. (2010). Accommodating (to) ELF in the international university. Journal of Pragmatics, 43(4), 926-936. http://dx.doi.org/10.1016/j.pragma.2010.05.011

Jensen, H., \& Johannesson, H. (1995). Engineering courses taught in English: an experience from Denmark. European Journal of Engineering Education, 20(1), 19-23. http://dx.doi.org/10.1080/0304379950200103

Jones, N., \& Lau, A. M. S. (2010). Blending learning: widening participation in higher education. Innovations in Education and Teaching International, 47(4), 405-416. http://dx.doi.org/10.1080/14703297.2010.518424

Jusoff, K., \& Khodabandelou, R. (2009). Preliminary study on the role of social presence in blended learning environment in higher education. International Education Studies, 2(4), 79-83. http://dx.doi.org/10.5539/ies.v2n4p79

Kahng, Y. (1999). Immersion education in Southeast Asia. English Language and Literature Teaching. 5, 79-101.

Kang, S., \& Park, H. (2005). English as the medium of instruction in Korean engineering education. Korean Journal of Applied Linguistics, 21(1), 155-174.

Kim, E. (2002). Voices of learners from English-medium lectures. Journal of the Applied Linguistics Association of Korea, 18(2), 145-163.

Kim, J. \& Choi, J. (2014). English for university administrative work: English officialization policy and foreign language learning motivation. English Language Teaching, 7(9), 1-13. http://dx.doi.org/10.5539/elt.v7n9p1

Kim, J. (2010). L2 Learner's perspectives of how personal and instructional factors influence achievement in online EFL learning environment. English Language \& Literature Teaching, 16(4), 39-69.

Kim, J. (2011). Relationships among motivation, contextual factors and achievement in on-offline blended English writing class. English Language \& Literature Teaching, 17(4), 97-122.

Kim, J. (2014). College EFL learners' speaking motivation under English-medium instruction policy. The Journal of Asia TEFL, 11(1), 71-96.

Kim, J., Tatar, B., \& Choi, J. (2014). Emerging culture of English-medium instruction in Korea: experiences of Korean and international students. Language and Intercultural Communication, 14(4), 441-459. http://dx.doi.org/10.1080/14708477.2014.946038 
Kirkgöz, Y. (2005). Motivation and student perception of studying in an English-medium university. Journal of Language and Linguistic Studies, 1(1), 101-122.

Knight, J. (1993). Internationalization: management strategies and issues. International Education Magazine, 9 , 21-22.

Knight, J. (2008). Higher Education in turmoil: The changing world of internationalization. Rotterdam, Canada: Sense Publishers.

Kong, S., \& Hoare, P. (2012). The development of academic language proficiency: challenges for middle school immersion in Hong Kong and Xi'an. International Education, 41(2), 88-127.

Lawton, D., Vye, N., Bransford, J., Sanders, E., Rickey, M., French, D., \& Stephens, R. (2012). Online learning based on essential concepts and formative assessment. Journal of Engineering Education, 101(2), 224-287. http://dx.doi.org/10.1002/j.2168-9830.2012.tb00050.x

Lee, K. C., \& Chong, P. M. (2007). An observational study on blended learning for Japanese language studies. In Fong, J., \& Wang, F. L. (Eds.), Blended learning (pp. 88-100). Edinburgh: Pearson.

Lim, C.-P., Zhao, Y., Tondeur, J., Chai, C.-S., \& Tsai, C.-C. (2013). Bridging the gap: Technology trends and use of technology in schools. Educational Technology \& Society, 16(2), 59-68.

Manakul, W. (2007). Role of English in internationalization of higher education: The case of the Graduate School of Engineering, Hokkaido University. Higher Education and Lifelong Learning, 15, 155-162.

Manh, L. D. (2012). English as a medium of instruction at tertiary education system in Vietnam. The Journal of Asia TEFL, 9(2), 97-122.

Merriam, S. B. (2009). Qualitative research: A guide to design and implementation. San Francisco: Jossey-Bass.

Ng'ambi, D., \& Lombe, A. (2012). Using podcasting to facilitate student learning: a constructivist perspective. Educational Technology \& Society, 15(4), 181-192.

Oh, H., \& Lee, H. (2010). Characteristics of effective English medium instruction and support measures. Modern English Education, 11(1), 191-202.

Onsman, A. (2012). Distributing the future evenly: English as the lingua franca in the Saudi Arabian higher education sector. Higher Education Policy, 25, 477-491. http://dx.doi.org/10.1057/hep.2012.8

Park, G., \& Lim, H. (2013). How writing in a social network site and bulletin board influences peer interactions and writing outcomes. Foreign Languages Education, 20(3), 169-195.

Park, Y. (2011). English-medium instruction in college. Paper presented at Annual Policy Forum -Korean Council for University Education on June 3, 2011. Seoul, South Korea

Piller, I. \& Cho, J. (2013). Neoliberalism as language policy. Language in Society, 42, 23-44. http://dx.doi.org/10.1017/S0047404512000887

Rooney, J. E. (2003). Knowledge infusion: Blending learning opportunities to enhance educational programming and meetings. Management Association, 55(5), 26-32.

Shin, H.-J., Peachey, J., \& Tuck, J. R. (2002). Adapting 'applied internet English' for partially online learning. Korean Journal of Applied Linguistics, 18(1), 175-194.

So, H.-J., \& Bonk, C. J. (2010). Examining the roles of blended learning approaches in Computer-Supported Collaborative Learning (CSCL) environment: A Delphi Study. Educational Technology \& Society, 13(3), 189-200.

Spector, J. M. (2013). Emerging educational technologies and research directions. Educational Technology \& Society, 16(2), 21-30.

Sun, Y-C. (2010). Extensive writing in foreign language classrooms: A blogging approach. Innovations in Education and Teaching International, 47(3), 327-339. http://dx.doi.org/10.1080/14703297.2010.498184

Tatzl, D. (2011). English-medium masters' programmes at an Austrian university of applied sciences: Attitudes, experiences and challenges. Journal of English for Academic Purposes, 10, 252-270. http://dx.doi.org/10.1016/j.jeap.2011.08.003

Teichler, U. (2004). The changing debate on internationalisation of higher education. Higher education, 48(1), 5-26. http://dx.doi.org/10.1023/B:HIGH.0000033771.69078.41

Thang, S. M., Mustaffa, R., Wong, F. F., Noor, N. M., Mahmud, N., Latif, H., \& Aziz, N. S. A. (2013). A 
quantitative inquiry into the effects of blended learning on English language learning: The case of Malaysian undergraduates. International Education Studies, 6(6), 1-7. http://dx.doi.org/10.5539/ies.v6n6p1

Tselios, N., Daskalakis, S., \& Papadopoulou, M. (2011). Assessing the acceptance of a blended learning university course. Educational Technology \& Society, 14(2), 224-235.

Tsuneyoshi, R. (2005). The dilemmas and possibilities of study abroad programs using English. Journal of Research in International Education, 4(1), 65-86. http://dx.doi.org/10.1177/1475240905050291

Vinke, A., Snippe, J., \& Jochems, W. (1998). English-medium content courses in non-English higher education: a study of lecturer experiences and teaching behaviours. Teaching in Higher Education, 3(3), 383-394. http://dx.doi.org/10.1080/1356215980030307

Wing, S. C., \& Khe, F. H. (2011). Design and evaluation of two blended learning approaches: Lessons learned. Australasian Journal of Educational Technology, 27(8), 1319-1337.

Witty, S. M. (2008). Language in context instructional language in EFL, English Language Education, 37, 68-81.

Wold, K. (2011). Blending theories for instructional design: creating and implementing the structure, environment, experience, and people (SEEP) model. Computer Assisted Language Learning, 24(4), 371-382. http://dx.doi.org/10.1080/09588221.2011.572900

Yamat, H., Umar, N. F. M., \& Mahmood, M. I. (2014). Upholding the Malay language and strengthening the English language policy: An education reform. International Education Studies, 7(13), 197-205. http://dx.doi.org/10.5539/ies.v7n13p197

Zhao, H., \& Coombs, S. (2012). Intercultural teaching and learning strategies for global citizens: a Chinese EFL perspective. Teaching in Higher Education, 17(3), 245-255. http://dx.doi.org/10.1080/13562517.2011.611874

\section{Copyrights}

Copyright for this article is retained by the author(s), with first publication rights granted to the journal.

This is an open-access article distributed under the terms and conditions of the Creative Commons Attribution license (http://creativecommons.org/licenses/by/3.0/). 